\title{
An Expeditious Synthesis of DPD and Boron Binding Studies
}

\author{
Martin F. Semmelhack, ${ }^{a^{*}}$ Shawn R. Campagna, ${ }^{a}$ Michael J. Federle, ${ }^{b}$ Bonnie \\ L. Bassler \\ Departments of Chemistry ${ }^{a}$ and Molecular Biology, ${ }^{b}$ Princeton University, \\ Princeton, NJ 08544
}

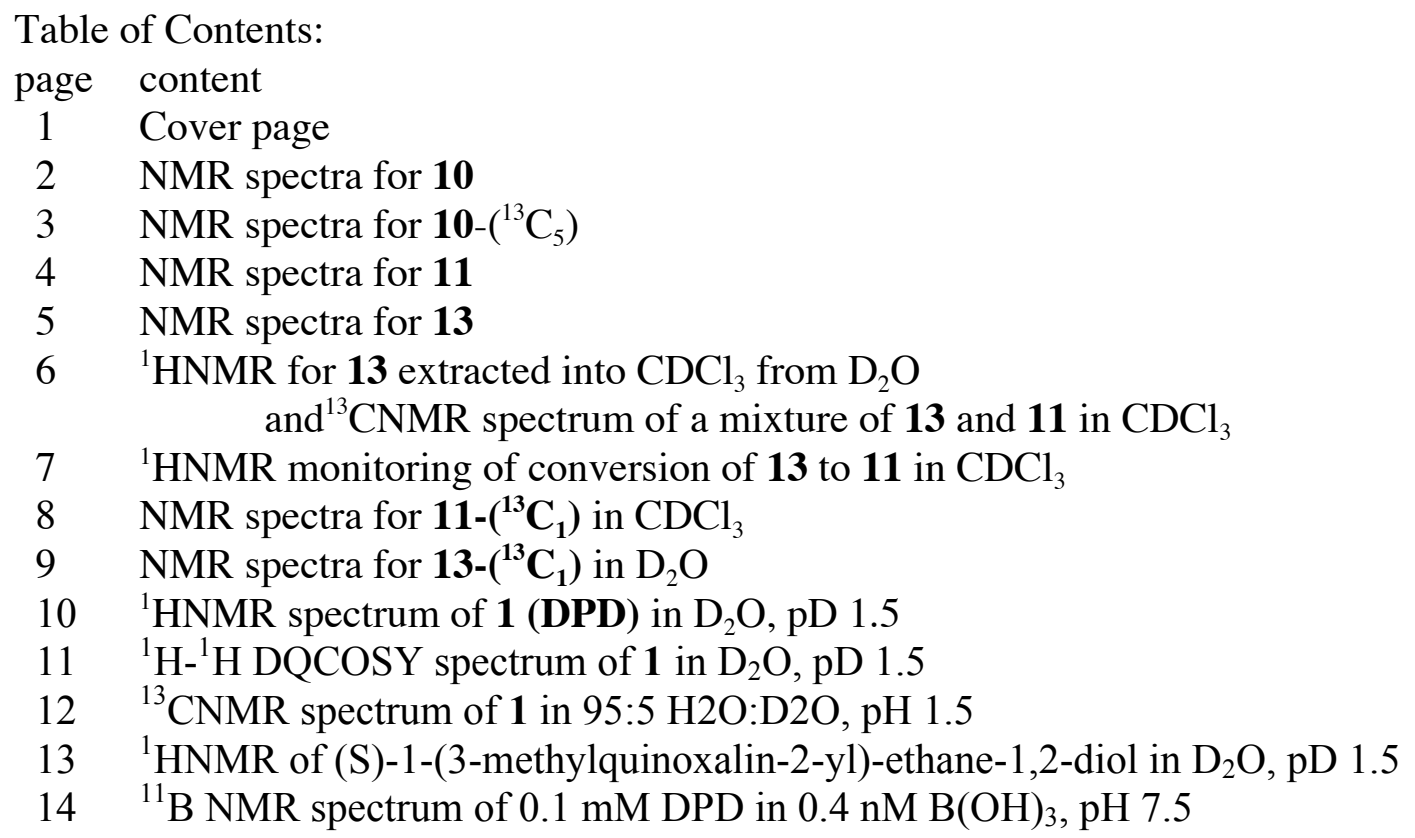




\section{${ }^{1} \mathrm{H}$ and ${ }^{13} \mathrm{C}$ NMR spectra of 10 in $\mathrm{CDCl}_{3}$}
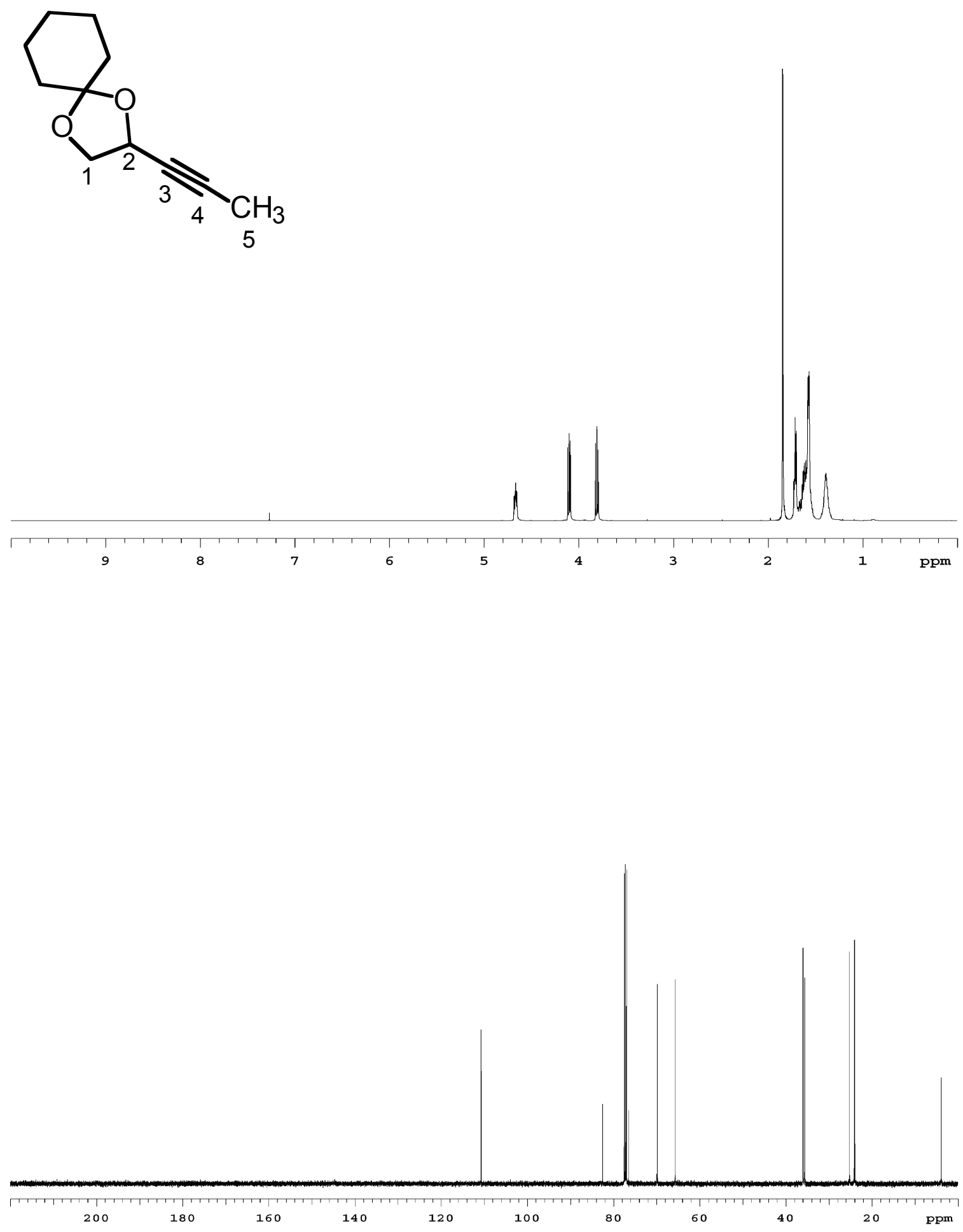


\section{${ }^{1} \mathrm{H}$ and ${ }^{13} \mathrm{C}$ NMR spectra of $10-\left({ }^{13} \mathrm{C}_{5}\right)$ in $\mathrm{CDCl}_{3}$}
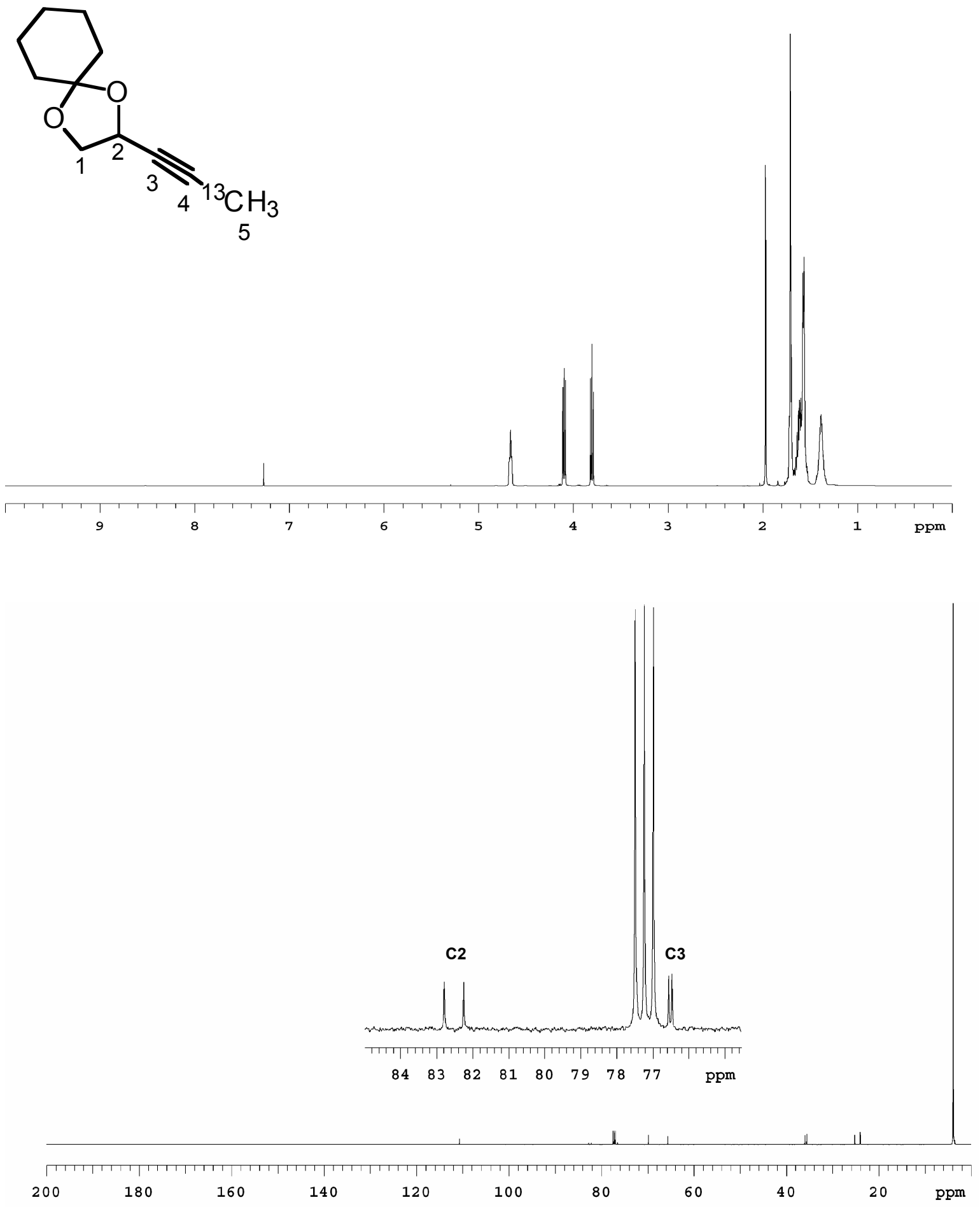


\section{${ }^{1} \mathrm{H}$ and ${ }^{13} \mathrm{C}$ NMR spectra of 11 in $\mathrm{CDCl}_{3}$}
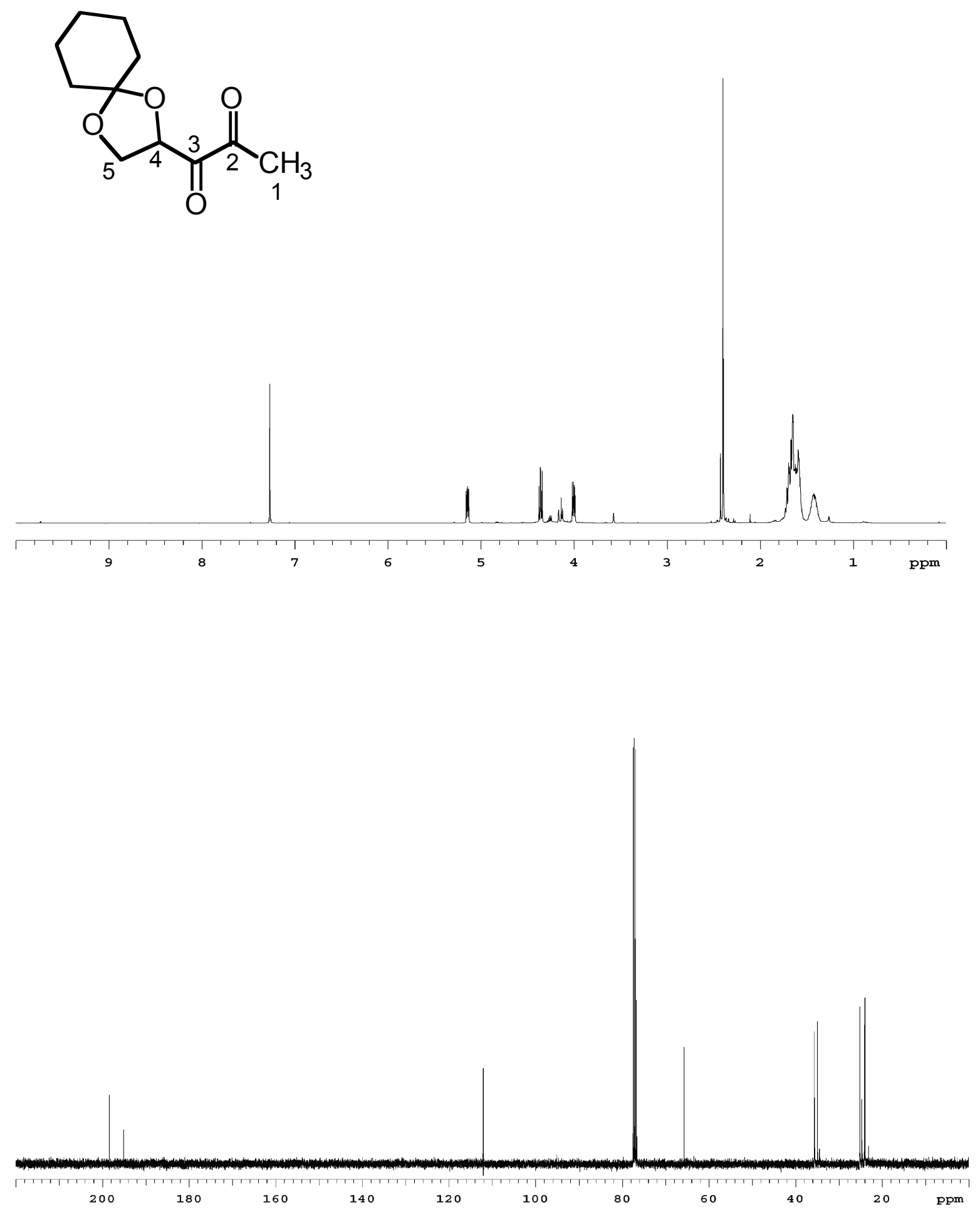


\section{${ }^{1} \mathrm{H}$ and ${ }^{13} \mathrm{C}$ NMR spectra of 13 in $\mathrm{D}_{2} \mathrm{O}$}
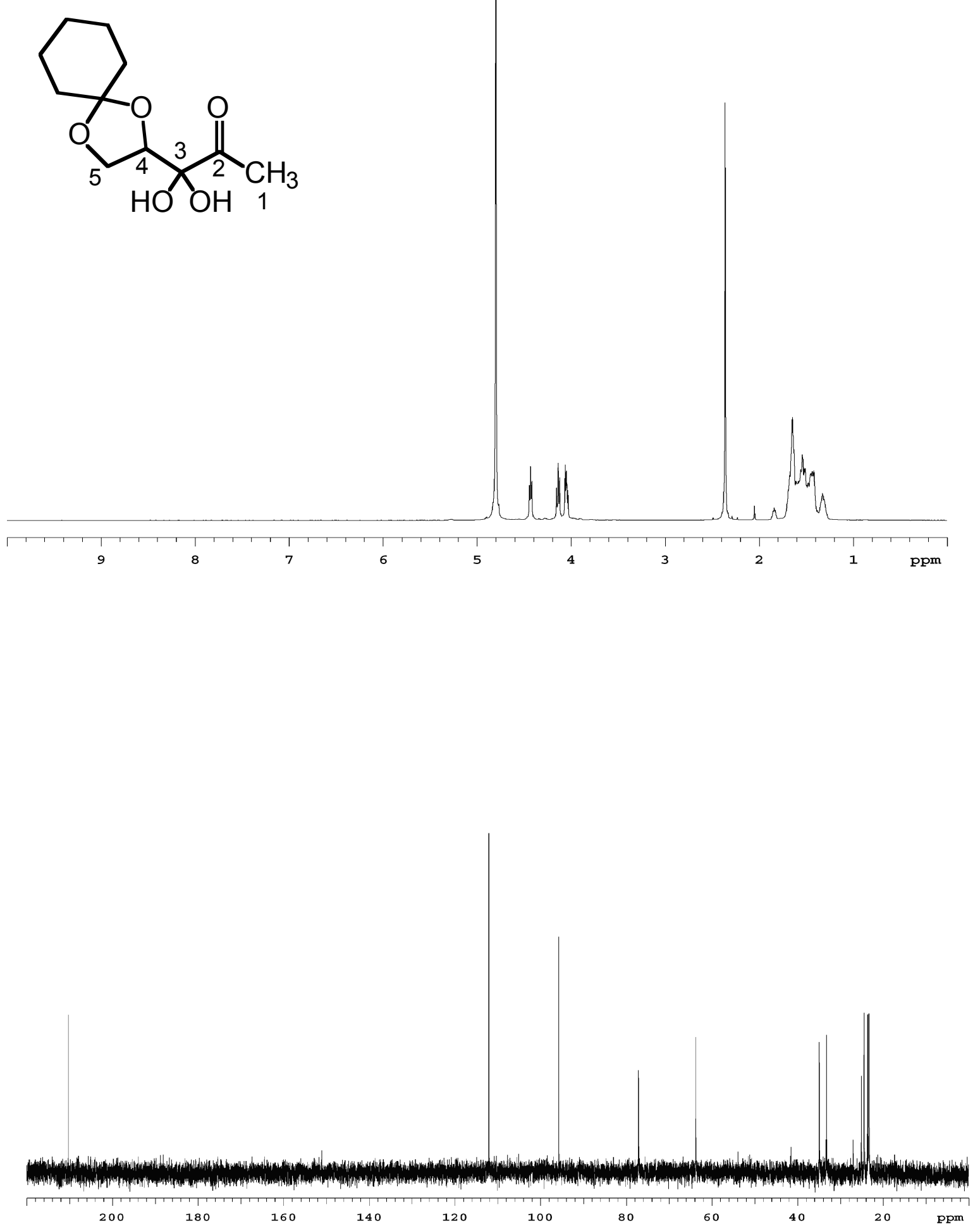
${ }^{1} \mathrm{H}$ NMR spectrum of 13 extracted into $\mathrm{CDCl}_{3}$ from $\mathrm{D}_{2} \mathrm{O}$<smiles>CCC(=O)C(O)(O)[C@H]1COC2(CCCCC2)O1</smiles>

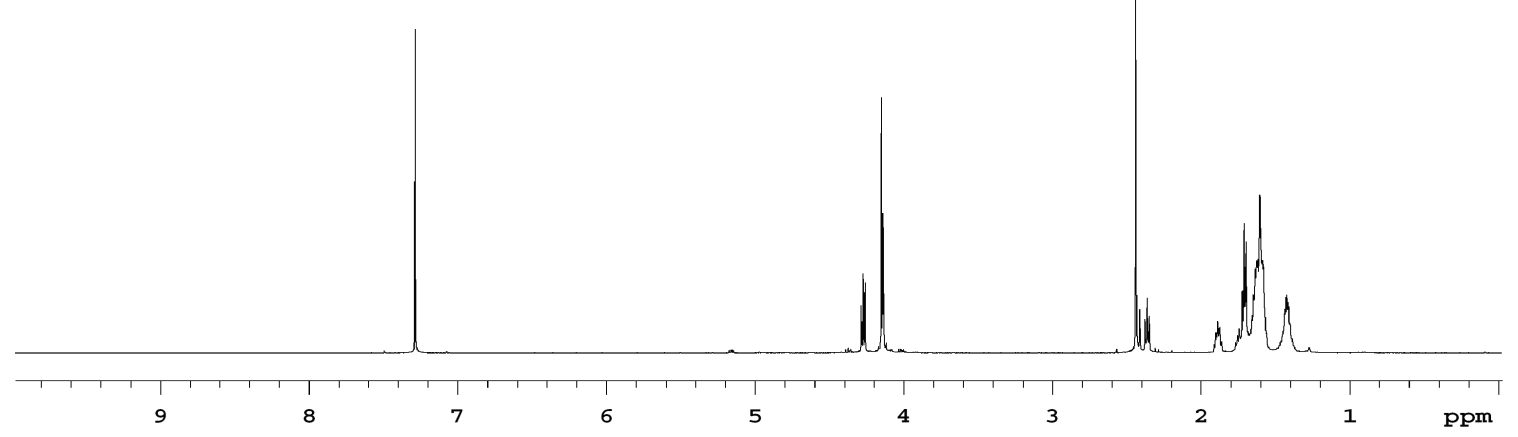

${ }^{13} \mathrm{C}$ NMR spectrum of a mixture of 13 and 11 in $\mathrm{CDCl}_{3}$<smiles>CC(=O)C(=O)[C@H]1COC2(CCCCC2)O1</smiles>

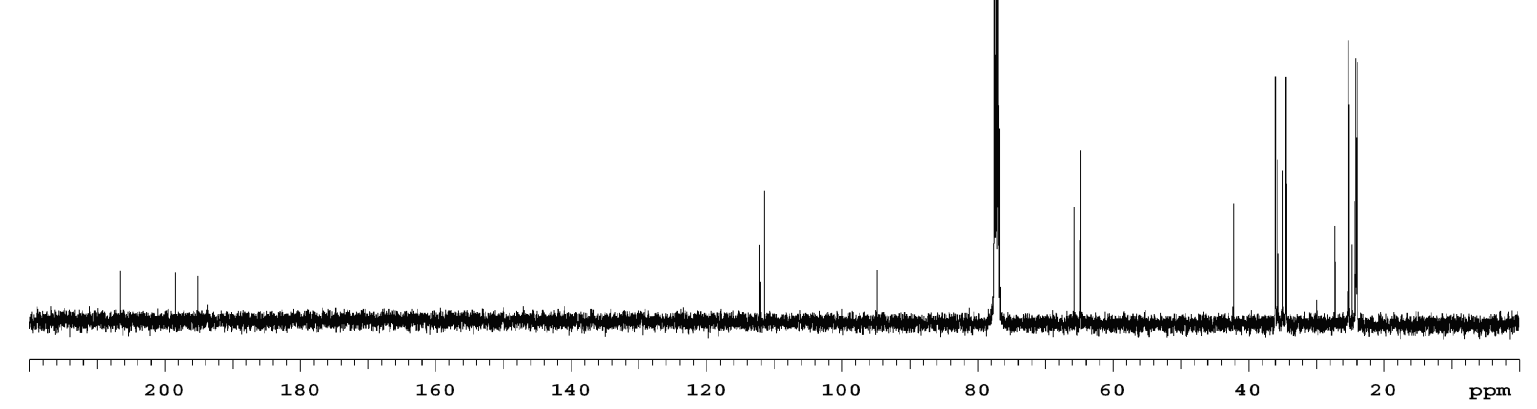




\section{${ }^{1} \mathrm{H}$ NMR monitoring of conversion of $\mathbf{1 3}$ to $\mathbf{1 1}$ after 26 $\mathrm{h}$ in $\mathrm{CDCl}_{3}$}
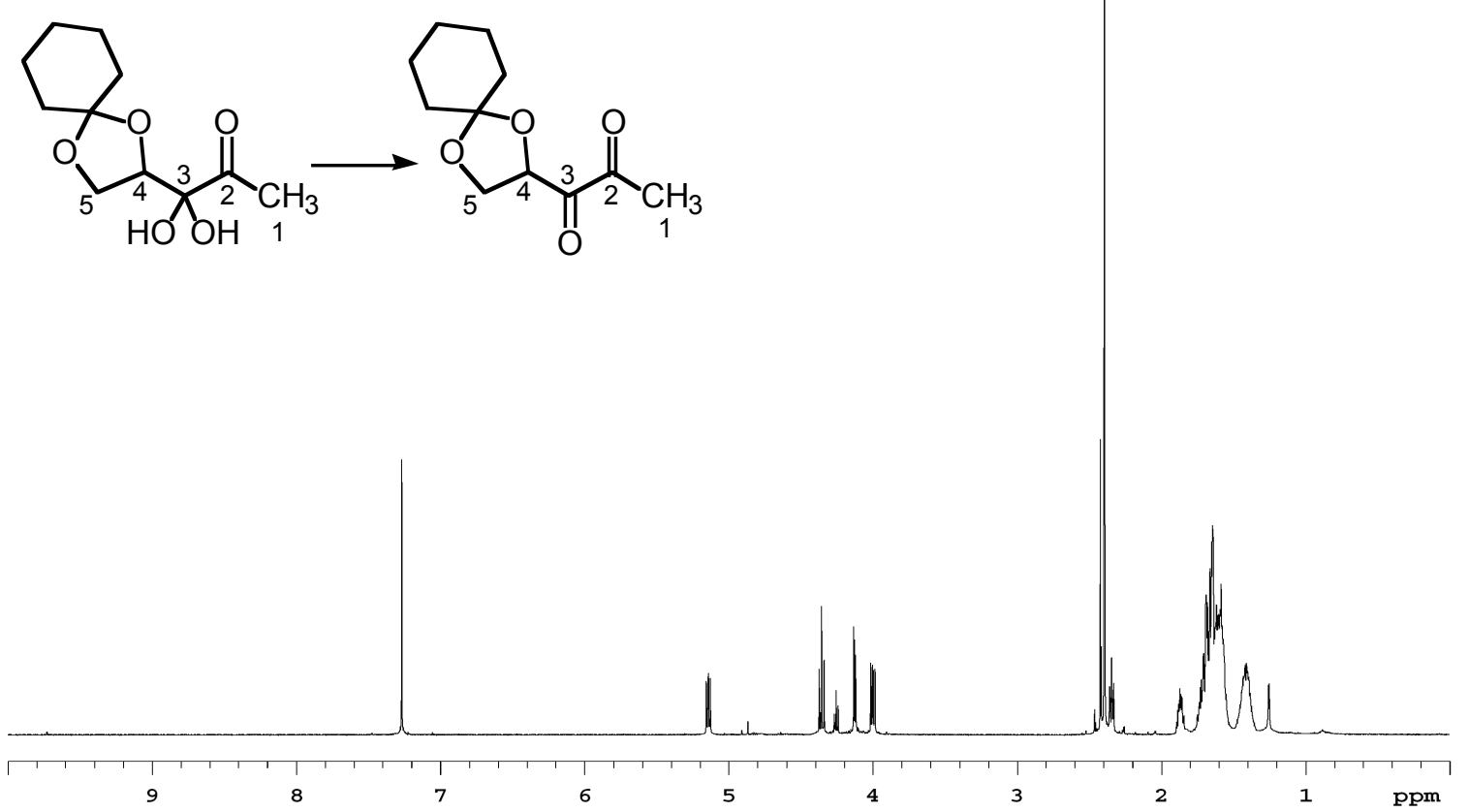


\section{${ }^{1} \mathrm{H}$ and ${ }^{13} \mathrm{C}$ NMR spectrum of $11-\left({ }^{13} \mathrm{C}_{1}\right)$ in $\mathrm{CDCl}_{3}$}
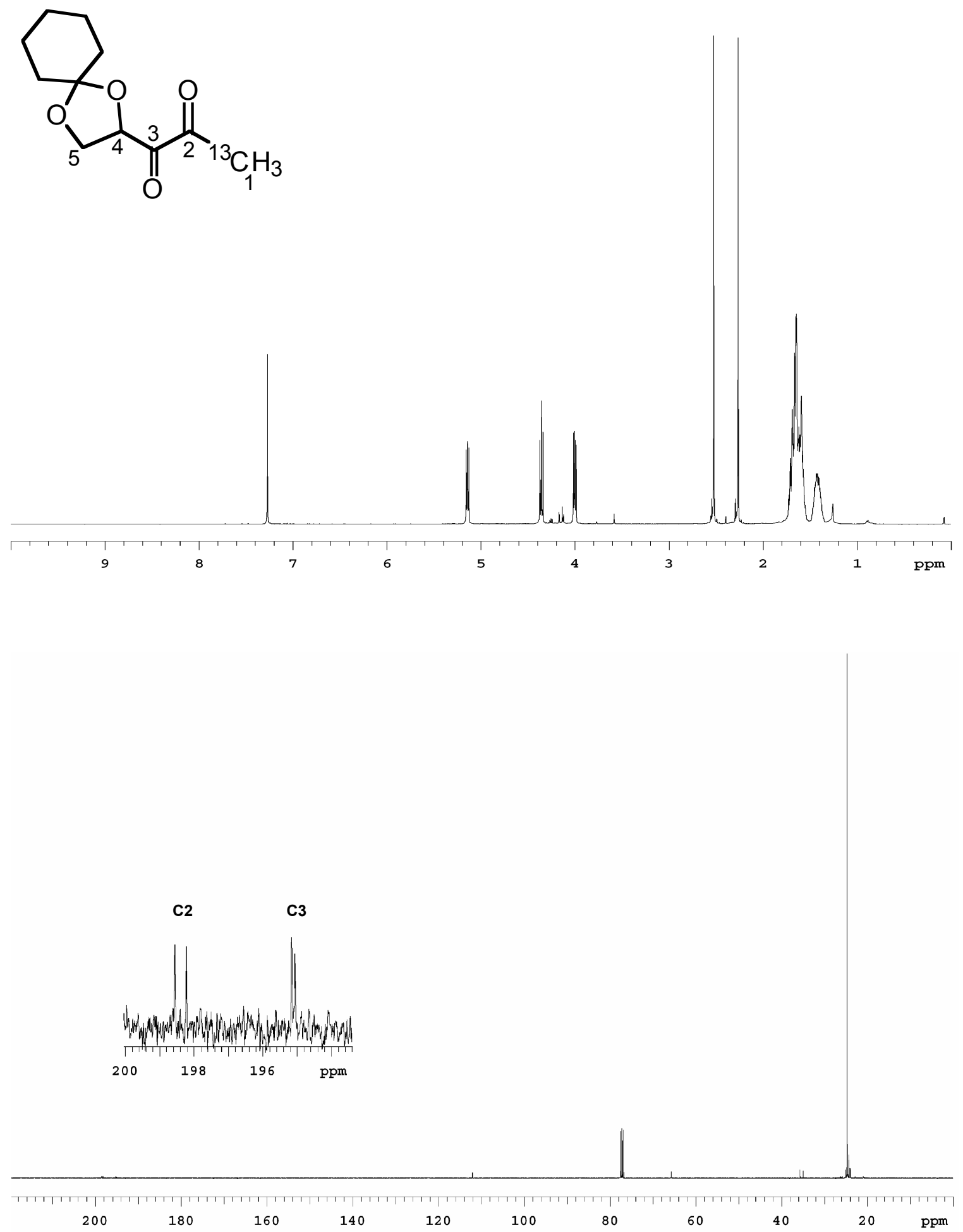


\section{${ }^{1} \mathrm{H}$ and ${ }^{13} \mathrm{C}$ NMR spectrum of $13-\left({ }^{13} \mathrm{C}_{1}\right)$ in $\mathrm{D}_{2} \mathrm{O}$}
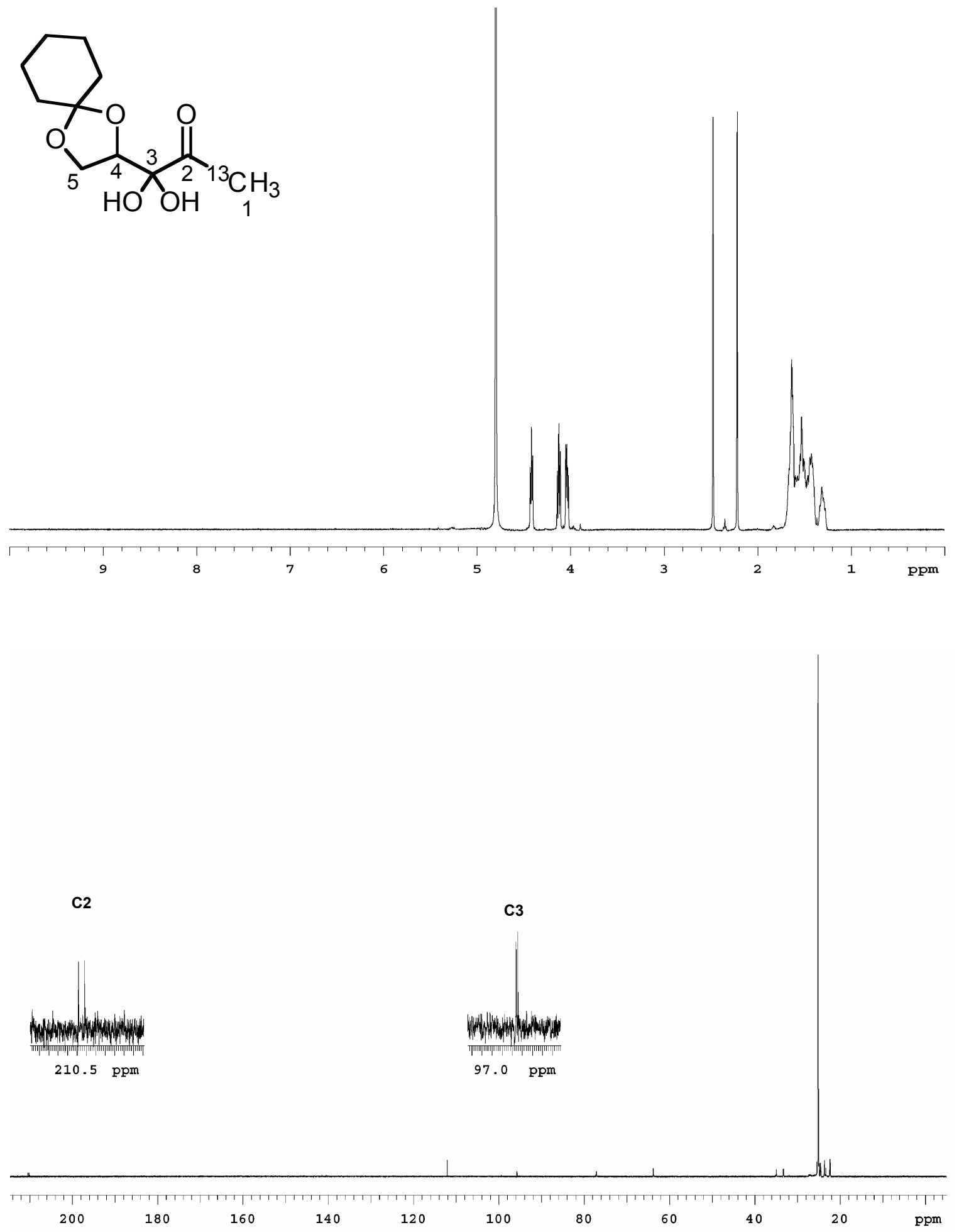


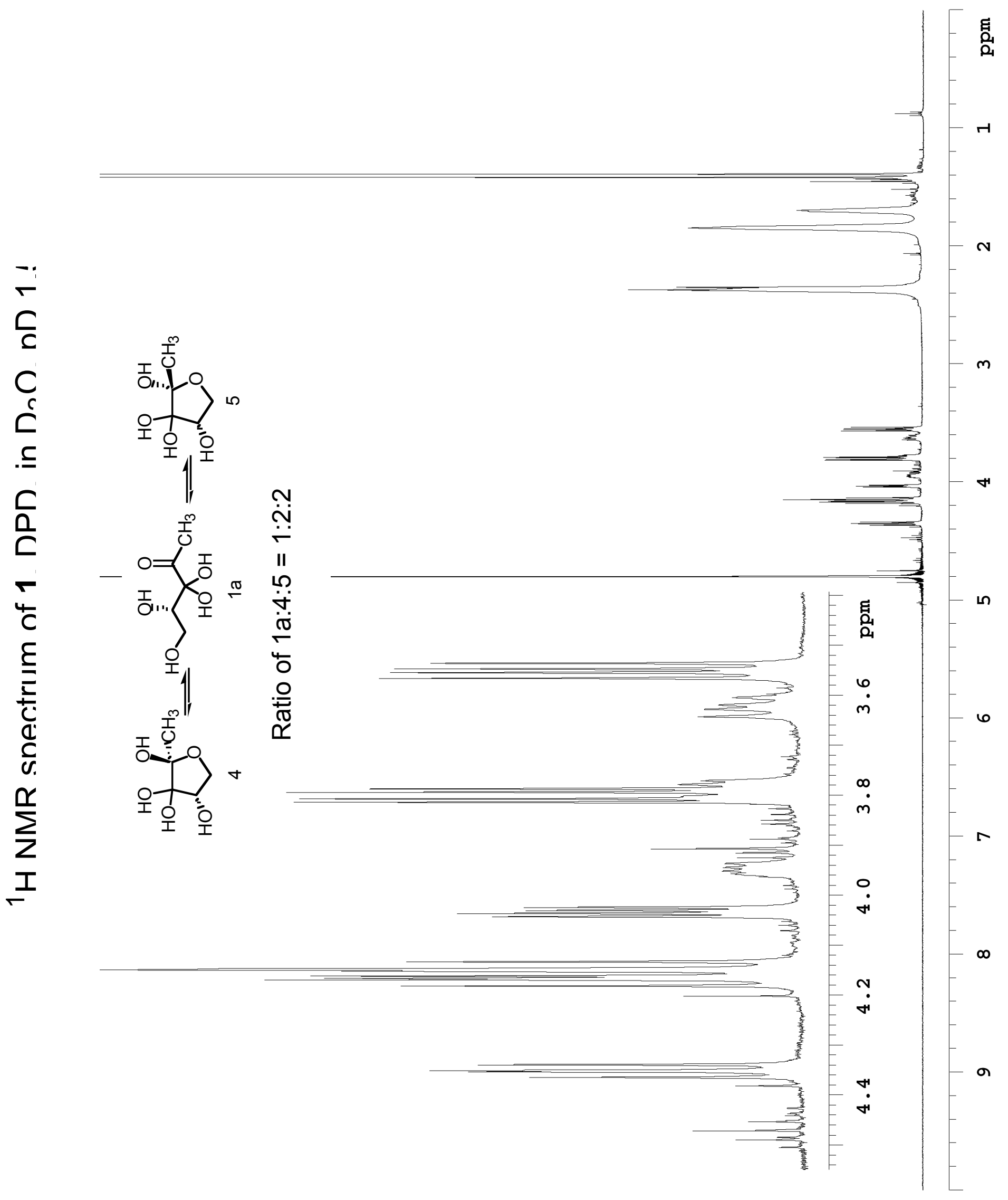




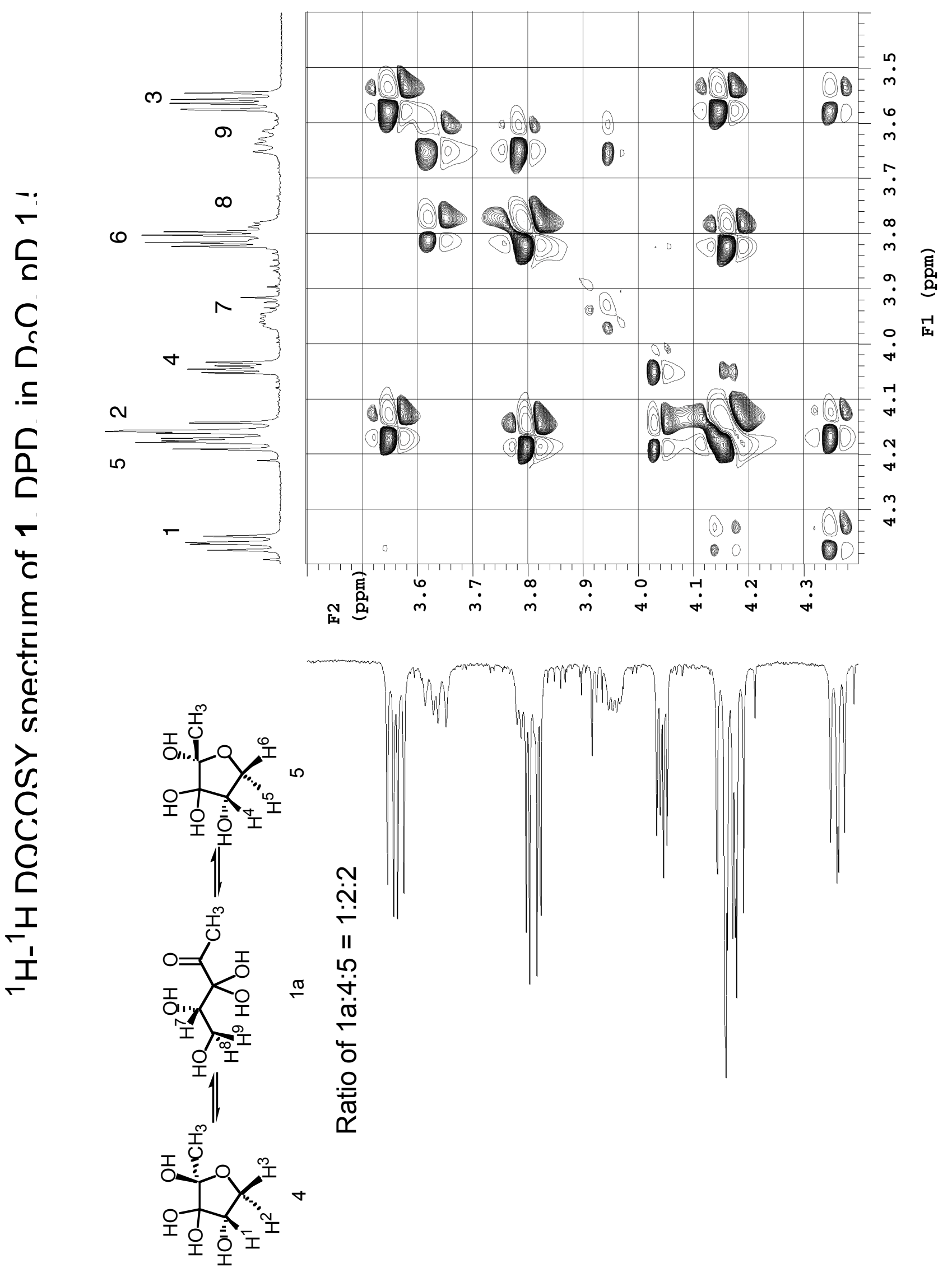




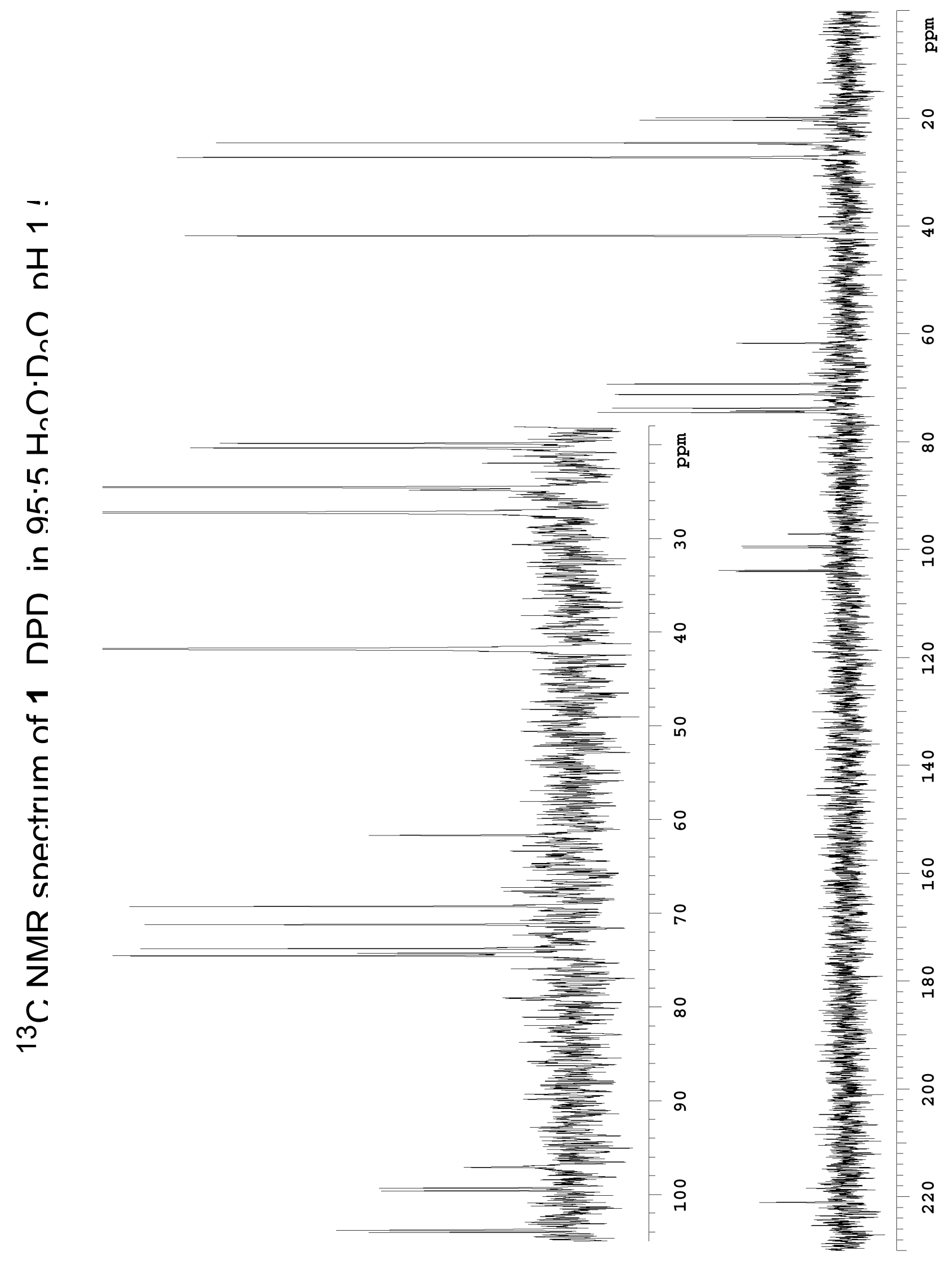




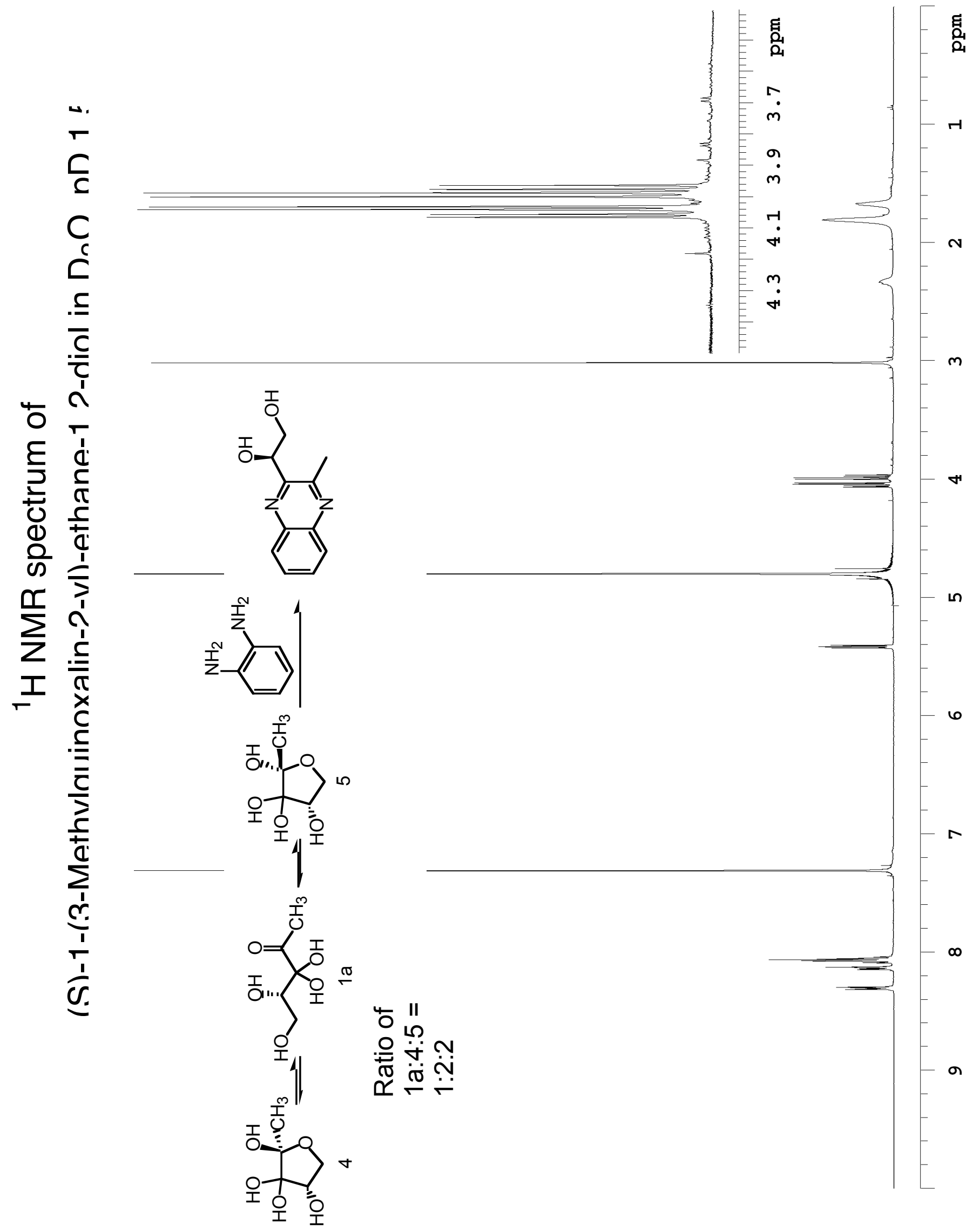




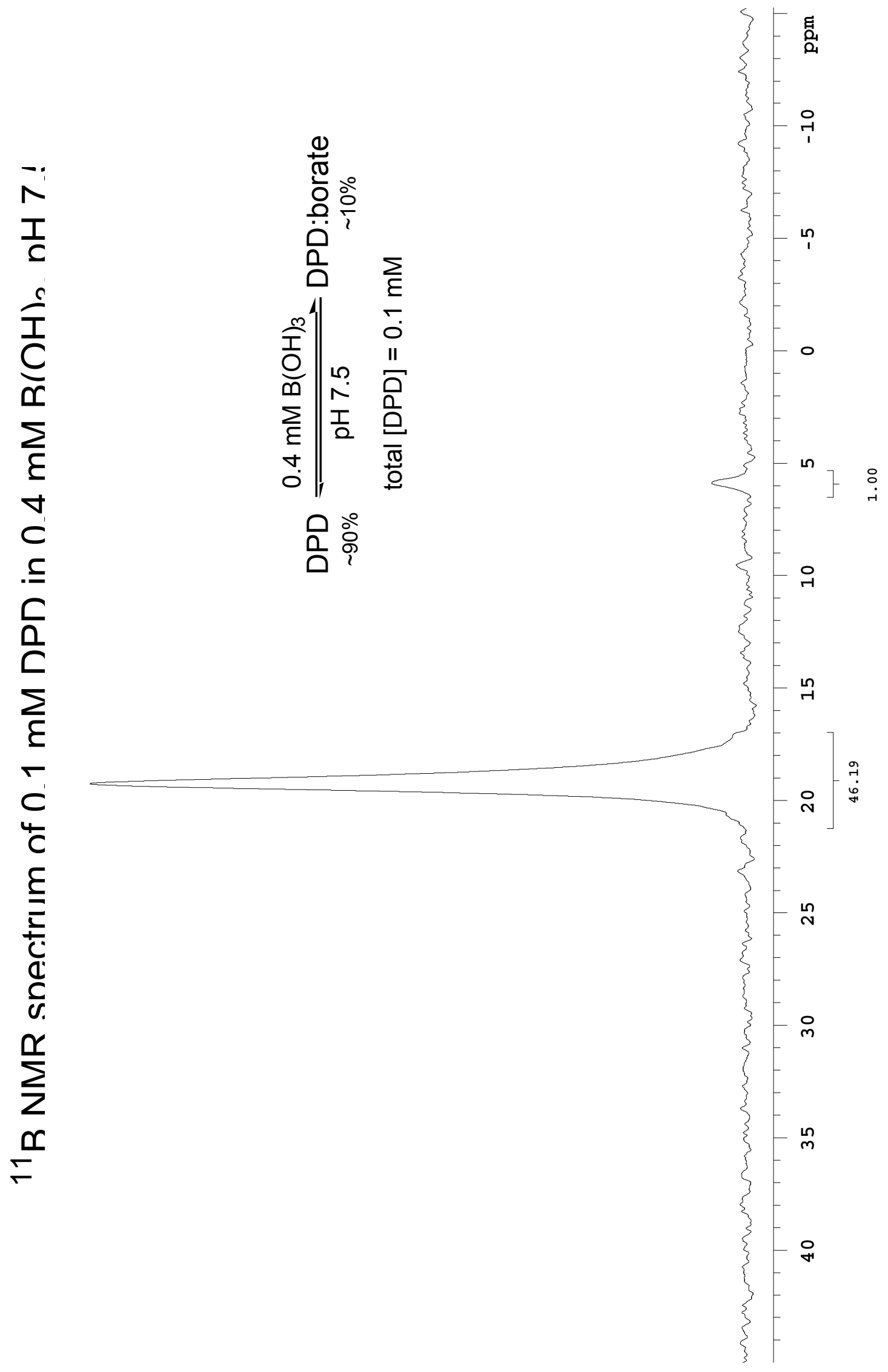

